\title{
Distintos puntos de vista acerca de las familias y los hogares en los padrones de población de la Capitanía de São Paulo, Brasil $(1765-1836)^{*}$
}

Carlos de Almeida Prado Bacellar

Profesor del Departamento de Historia

Universidad de São Paulo cbacellar@usp.br

Recibido: julio de 2014

Aprobado: septiembre de 2014

Resumen: La Corona portuguesa estableció una política de encuestas periódicas a los habitantes de la Capitanía de São Paulo desde 1765, a través de la preparación de padrones anuales de población. Dicha capitanía, una región económicamente periférica, pero militarmente estratégica para los intereses de la metrópoli, fue la única del Imperio portugués que tuvo un sistemático seguimiento estadístico durante mucho tiempo. Las condiciones para la elaboración de estos censos fueron variables a lo largo de los años, no

* Agradecemos la colaboración de Carlos Costa Molina, historiador graduado en la Universidad de Cartagena, por la impecable traducción de este artículo del portugués al español.

EL TALLER DE LA HISTORIA, vol.7, n. ${ }^{\circ}$ 7, 2015, págs. 141 -168. Issn: 1657-3633; e-Issn: 2382-4794. Programa de Historia, Facultad de Ciencias Humanas, Universidad de Cartagena de Indias, Colombia 
solamente debido a las constantes modificaciones implementadas desde Lisboa, sino también por las dificultades en el trabajo exigido a una gran variedad de oficiales de milicias sin entrenamiento para una tarea de tal envergadura. Un gran volumen de información se recabó con éxito extraordinario para esta población; pero los problemas de fiabilidad subyacentes en estas fuentes son inevitables. En este artículo se analiza la calidad y la confiabilidad de la información ofrecida por esta extensa serie documental, procurando identificar sus deficiencias e incongruencias.

Palabras claves: Capitanía de São Paulo, padrones de población, Compañías de Ordenanzas, mapas de población, hogares, lares.

\section{Presentación}

Los padrones de población en la América portuguesa son series documentales bastante conocidas pero paradójicamente poco exploradas por los historiadores brasileños a lo largo de las últimas décadas. Su distribución entre los archivos es extremadamente desigual; abundantes para los casos de la Capitanía de São Paulo y el Gran Pará, pero escasas, por no decir inexistentes, para otras regiones del Brasil portugués. Todavía no se sabe con exactitud si la ausencia de otras series completas, parecidas a la de São Paulo, se deba a la indiferencia burocrática para realizarlas en todas las capitanías. Sin embargo, existe la posibilidad que tal ausencia de un mayor número de censos de población, que aún se conservan en los archivos, sea por desgracia la prueba concreta de la negligencia en la custodia de la documentación de nuestro pasado.

Hay indicios bastante consistentes que comprueban que las ejecuciones de los padrones de población llegaron a ser considerablemente aplicadas por los gobernadores portugueses en las diversas posesiones ultramarinas desde principios 
del siglo XVIII. ${ }^{1}$ Pero recientes balances revelan una práctica más generalizada en el levantamiento de cuadros de resumen de población en lugar de censos detallados por habitantes. De todos modos, no se sabe con certeza si los cuadros de resumen estadístico se construyeron a partir de padrones de población o no.

En los territorios del actual Brasil los padrones de población empezaron a realizarse tan sólo a partir de 1765 , dentro del contexto de toda una política preocupada con la reorganización del mundo colonial. Un movimiento que iría de la mano con las proyecciones de otros estados europeos, haría surgir en Portugal el interés por aprender más sobre el potencial demográfico y económico de sus posesiones y también del propio territorio metropolitano. Para el caso concreto de la capitanía de São Paulo, el gobernador y capitán general recién posesionado, Luis Antonio Botelho de Sousa Mourão, Mayorazgo de Mateus, despacha ordenes en ese sentido antes de llegar al puerto de Santos en 1765, proveniente de Río de Janeiro, en donde había recibido instrucciones pormenorizadas del virrey Conde da Cunha. ${ }^{2}$ Durante las décadas siguientes, los censos de habitantes seguirían siendo minuciosamente preparados en São Paulo, cada vez más detallados debido al surgimiento de nuevas demandas administrativas.

La gran cantidad de información de esta serie, que abarca todos los pueblos y sus respectivos hogares en la entonces capitanía de São Paulo (incluyendo el territorio del actual Estado de Paraná), es notable. Es admirable el esfuerzo dedicado al trabajo de seguimiento anual a una población esparcida por un vasto territorio, en su mayor parte asentada fuera de los pequeños y escasos núcleos urbanos. Aprovechándose la estructura preexistente de las Compañías de Ordenanzas, el tradicional cuerpo militar de reservistas instalado en cada municipio del Imperio portugués, se logró obtener un panorama bastante conciso de todos los residentes, libres o esclavos, observados en sus historias de vida por alrededor de setenta años.

\footnotetext{
1 Paulo Matos, "O numeramento de Goa de 1720", en Anais de História de Além-Mar vol. III, Lisboa, 2007, pp.241-324.

2 Heloisa Bellotto, Autoridade e conflito no Brasil colonial: o governo do Morgado de Mateus em São Paulo, São Paulo, Alameda, $2^{\text {a }}$ ed. revista, 1979, p.79.
} 
De una manera más general, puede considerarse que los padrones comenzaron a informar la actividad económica de cada hogar sólo a partir de 1798, cuando hay nuevas directrices procedentes de Lisboa.

\begin{tabular}{||l|l||}
\hline Alexandre Cursino dos Santos, 34, casado, blanco, & Sembrador \\
natural de Taubaté & Recoge 3o fanegas de maíz, 6 al- \\
Ana Clara, mujer, 28, casada, blanca, natural de São & queires de fríjol \\
Luis & Tabaco 20 arrobas que vende a 820 \\
en la zona \\
Antonio, hijo, 1, soltero, blanco & Consumo de Sal 2 alqueires que \\
Francisca, hija, 5, soltera, blanca & compra en la zona a 1.920 \\
\hline
\end{tabular}

En el caso anterior, tenemos a una típica familia nuclear de pequeños agricultores, una joven pareja y sus tres hijos en la infancia. Son labriegos, aquí denominados sembradores, registrados para el año de 1801 en la villa de São Luiz de Paraitinga. Eran así pequeños productores de maíz y tabaco. ${ }^{3}$ Tiempo después se encuentra a la misma familia en el padrón de población de 1828 .

\begin{tabular}{|c|c|}
\hline $\begin{array}{l}\text { Alexandre Cursino dos Santos, 63, viudo, blanco, natural de } \\
\text { Taubaté } \\
\text { Joaquim, hijo, 15, soltero, blanco } \\
\text { João, hijo, 9, blanco } \\
\text { Luis, hijo, 10, blanco } \\
\\
\text { José, esclavo, 29, casado, negro, mozambique } \\
\text { Antônio, esclavo, 28, soltero, negro, congo } \\
\text { Rita, esclava, 22, casada, negra, conga } \\
\text { Eva, esclava, 1, negro, criolla } \\
\text { Gertrudes, agregada, 13, soltera, parda }\end{array}$ & $\begin{array}{l}\text { Agricultor } \\
\text { Tiene ingenio, y vende } 80 \text { ba- } \\
\text { rriles de aguardiente con- } \\
\text { sumidos en la región } \\
\text { Sal } 24 \text { alqueires procedentes } \\
\text { de Paraty } \\
\text { Vendió } 10 \text { cerdos, a 10.0oo y } \\
\text { fueron enviados a Paraty } \\
\text { Cresce la esclava Eva nacida, } \\
\text { faltan } 2 \text { hijos que se casaron }\end{array}$ \\
\hline
\end{tabular}

3 Arquivo Público do Estado de São Paulo (APESP), Lista nominativa de São Luiz do Paraitinga para 1801, $1^{\text {a }}$ Companhia de Ordenanças, f.21. 
Pasados veintisiete años, encontramos al jefe de la familia anciano, con 63 años de edad y en condición de viudo. Se sabe por el seguimiento sucesivo de los padrones, que su esposa Ana Clara falleció entre 1824 y 1825. Muchos de sus hijos ya han salido de la casa paterna para 1828 y el censo indica que recién realizado este se habían casado dos de ellos. Significativamente, se ve que Alexandre logró un ascenso social: ya no es un simple sembrador, se convirtió en señor de ingenio, productor de aguardiente. La lista de 1818 informa que en aquel año se construyó el ingenio. No era de gran tamaño, como lo confirma la pequeña producción y el reducido número de esclavos: tres adultos africanos y una niña criolla, muy probablemente hija de la pareja José y Rita. ${ }^{4}$

Sin embargo, la calidad y el volumen de la documentación no deberían impedir la crítica a la misma como fuente. Tal revisión no implica descalificación, pero sí el establecer mejores parámetros para su análisis, señalando las carencias y deficiencias en la información contenida. Entendida dentro del contexto en que fue elaborada, podemos comprender mejor qué informan sus líneas y entre líneas, así como escudriñar en sus vacíos. La población y la economía que desfilan por cada página que componen estos censos pasaron por el tamiz de una mirada muy centrada, preocupada por los problemas que se demandaban desde Lisboa. A pesar de ello, no siempre ese funcionario colonial comprendía lo que se le solicitaba, y si lo entendía, no se esmeraba como debía ser; dejaba descuidado el trabajo exigido, tal vez considerándolo una carga, un servicio más sin recompensas. Otros en cambio, más celosos del encargo requerido, se esforzaron en el levantamiento de los informes de población, incluso reproduciendo cuidadosas cubiertas acuareladas, dándole un toque refinado y personal al servicio cumplido. El historiador al enfrentar este tipo de fuente debe separar el trigo de la paja, detectar sus problemas, las falsificaciones, el trabajo descuidado, pero sobre todo, las intenciones detrás de la descripción enviada a los superiores. ¿Qué se pretendía mostrar y qué se deseaba ocultar? ¿Qué realidades no despertaban el interés administrativo? ¿Qué informaciones el funcionario colonial indagado pretendió enmascarar? Todas estas inquietudes que sirven de telón de fondo para las siguientes apreciaciones.

4 APESP, Lista nominativa de São Luiz do Paraitinga para 1828, $4^{\mathrm{a}}$ Companhia de Ordenanças, f.465.

Dossier: Cuestionando las fuentes de archivos: padrones de población, familias y sociedades coloniales en Iberoamérica, ss. XVIII-XIX 
Los padrones de población tuvieron a lo largo de las décadas en las que fueron elaborados diferentes y muy conocidas motivaciones. Como bien mostró Maria Luiza Marcílio, estos fueron concebidos inicialmente como instrumentos de apoyo al proceso de reclutamiento militar en el difícil contexto del conflicto con los españoles por la posesión de territorios alrededor de la Cuenca del Plata. ${ }^{5}$ Las tropas militares eran muy necesarias para enfrentar al enemigo, por tanto es significativo que la orden para la realización del primer padrón en 1765, se acompaña de una extensa correspondencia interesada en el reclutamiento, en la situación militar de la Colonia del Sacramento y en los movimientos de los gobiernos de Asunción y Buenos Aires. Fue a la vez, una coyuntura de fuertes y controvertidos cobros de impuestos en las regiones mineras de la Capitanía de Minas Gerais, asunto que el propio mayorazgo de Mateus resaltaba en incontables ocasiones en su correspondencia. ${ }^{6}$

El temor al fisco y a la recluta añadió sin duda el establecimiento de un ambiente propicio para las reacciones miedosas y desconfiadas entre los habitantes de São Paulo, tras la solicitud de informaciones acerca de sus ingresos y composición familiar. ¿Qué preguntas fueron aquellas que las autoridades (capitán mayor, capitanes de ordenanzas y demás oficiales) tanto querían saber acerca de la vida de cada uno? Marcílio advierte del evidente subregistro del contingente masculino en más de un padrón, lo que refleja una estrategia de escape al riesgo no deseado del reclutamiento militar. ${ }^{7}$ La construcción de simples pirámides poblacionales por edades inscritas demuestra un desequilibrio atípico entre los sexos en la edad adulta, sólo explicable por la reticencia que la elaboración del documento inspiraba en los hogares. Participar en las luchas mal comprendidas en el extremo sur de la

\footnotetext{
${ }^{5}$ María Luiza Marcílio, Crescimento demográfico e evolução agrária paulista, 170o-1836, São Paulo, Hucitec/Edusp, 2000, pp.33 y siguientes.

6 La región minera de la Capitanía de Minas Gerais enfrentó a comienzos de la segunda mitad del siglo XVIII una caída significativa en sus ingresos debido al agotamiento de las vetas auríferas. En respuesta, la Corona portuguesa buscó por todos los medios, incluso coercitivos, revertir el desplome de tales rentas.
}

${ }_{7}^{7}$ M. L. Marcílio, Crescimento demográfico e evolução agrária paulista, 170o-1836, p.78. 
América portuguesa no era exactamente el deseo de los jóvenes varones ni el de sus padres, más bien preocupados por la ardua lucha diaria por la supervivencia. ${ }^{8}$

Más allá de la resistencia a las encuestas, el ambiente poco ilustrado muy probablemente también contribuyó en las dificultades del resultado final. Los funcionarios encargados de recoger y sistematizar la información tenía sus limitaciones personales: en cuanto al desplazamiento y la falta de tiempo, así como un mayor o menor interés en colaborar. Aun así, el resultado global es notable y singular, tanto en la cobertura temporal como geográfica. Todo un rico universo humano fue rigurosamente seguido durante décadas, con una variedad de información particularmente sorprendente. Se abarcaron de la mejor forma posible rincones remotos, regiones agrestes aisladas y vías prolongadas; todo en un impresionante esfuerzo coordinado. El resultado final, tras el análisis de casi un siglo, es una serie documental uniforme con cualidades y defectos.

Los problemas con la veracidad en la información recogida se pueden detectar incluso en el primer padrón de 1765. Para su elaboración, el mayorazgo de Mateus había dado órdenes en el sentido de que se informara, por parte de los capitanes mayores encargados de tal labor, acerca del importe del patrimonio de cada hogar. Los datos suministrados fueron objeto del célebre artículo de Alice Canabrava, ${ }^{9}$ dando lugar a la afirmación de que São Paulo era efectivamente en aquel momento una capitanía periférica, decadente y pobre en el contexto de la América lusitana. ${ }^{10}$ Aunque los niveles de riqueza no son exactamente elevados, hasta el mo-

\footnotetext{
8 Existen casos de padrones en las que alguna autoridad consigna a lápiz, y por cada hogar, las expresiones "comprueba" o "no comprueba", lo que indica el cuidado por confirmar las informaciones recibidas. En otras situaciones, los padres se esforzaban en librar a sus hijos de esa carga indeseada, como fue el caso del capitán José Pereira de Castro, de la villa de São Luiz de Paraitinga, que en 1828 logró la exención del reclutamiento de dos de sus hijos: Francisco de 20 años y Luis de 21.

9 Alice Canabrava, "Uma economia de decadência: os níveis de riqueza na Capitania de São Paulo, 1765-67”, en Revista Brasileira de Economia vol.26, n. ${ }^{\circ}$ 2, Rio de Janeiro, 1972, pp.95-123,

${ }^{10}$ Maria Luiza Marcílio ha demostrado que tal decadencia es una falacia, ya que para que esta existiera, hubiera sido necesario disponer de un período anterior de riqueza que no hubo (M. Marcílio, Crescimento Demográfico). También Ana Paula Medicci ratificó, con bastante propiedad, cómo esta afirmación de una capitanía empobrecida se había originado dentro de los discursos de algunos sectores económicos que buscaban ventajas para sus negocios locales y trasatlánticos. (Anna Paula Medicci, Administrando conflitos: o exercício do poder e os interesses mercantís na capita-
}

Dossier: Cuestionando las fuentes de archivos: padrones de población, familias y sociedades coloniales en Iberoamérica, ss. XVIII-XIX 
mento se tienen evidencias consistentes de que los valores declarados se subestimaron, sobre todo al ser comparados con el patrimonio señalado en los inventarios post mortem; e incluso, si tomamos en cuenta que tales inventarios eran también sujeto de sospechas (en el mismo sentido) de fraude fiscal. Los análisis realizados por Maria Aparecida de Menezes Borrego han permitido identificar de manera contundente las notorias diferencias entre los valores globales de los activos contenidos en ambas fuentes. ${ }^{11}$

Hallazgos similares han indicado lo obvio: las fuentes documentales no pueden ser utilizadas sin un arsenal crítico consistente. No se trata por supuesto de recomendar el no uso de estas, pues son profundamente ricas y únicas en la diversidad de información contenida, pero sí el de hacer un análisis de las mismas en el contexto en el que fueron producidas y no aceptar de antemano las informaciones que se ofrecen como verdades absolutas, ya que podrían ser inexactas o deliberadamente engañosas.

En este sentido, se debe prestar mucha atención a las condiciones que se tuvieron a la hora de elaborar los padrones. Es en el propio historiador en quien debe recaer la responsabilidad por considerar las enormes dificultades que los funcionarios públicos enfrentaron en el momento de llevar a buen término la deseada encuesta poblacional. Villas con extensos territorios, con precarias vías de comunicación y parte de la población ubicada en zonas áridas del interior de la provincia, no constituían exactamente un panorama facilitador de la actividad encuestadora. Montar a caballo e ir por todos los rincones de un poblado era todo un reto, enfrentándolo con mayor o menor entereza conforme a lo encargado. A parte de eso, era

nia/província de São Paulo (1765-1822), Tesis de doctorado en Historia Social de la Universidad de São Paulo, 2010, pp.31 y siguientes).

${ }^{11}$ La autora cita dentro de otros ejemplos, dos casos significativos. Domingos João Vilarinhos, cuyos bienes se evalúan por valor de $500 \$ 000$ en el padrón de 1765, tiene en su propio inventario realizado al año siguiente la cifra de 2:280\$295. Doña Maria da Silva Leite, cuya aparcería de su marido fue evaluada en 1762 por valor de 28:179\$204, declaró en 1765 tan sólo 10:000\$ooo de patrimonio. Maria Borrego, A teia mercantil: negócios e poderes em São Paulo colonial (1711-1765), São Paulo, Alameda, 2010, p.230.

Dossier: Cuestionando las fuentes de archivos: padrones de población, familias y sociedades coloniales en Iberoamérica, ss. XVIII-XIX 
necesario hacer frente a la desconfianza y al miedo a las preguntas formuladas por las autoridades. ${ }^{12}$

Hipotéticamente cada compañía de ordenanza, bajo su vigilancia, tenía a la población empadronada por medio de un capitán, quizás ayudado por los cabos de escuadra, ya que así debía corresponderse al orden de la delegación de funciones, de acuerdo a la división jerárquica de cada compañía. El capitán era en todo caso quien firmaba como responsable de los datos facilitados. Son evidentes las particulares autorías de los distintos secretarios; cambiaban desde el papel, la tinta y la caligrafía, hasta la calidad de la información recogida. No se sabe a ciencia cierta si las falencias en la calidad surgieron de la comprensión distorsionada de las instrucciones recibidas, por falta de voluntad al ejecutarlas o por la conjugación de ambas razones. De cualquier forma, lo menos que se puede considerar es que las encuestas de cada compañía, reunidas en manos de los respectivos capitanes mayores de las villas, fueron aceptadas en las condiciones en que habían sido entregadas, a pesar de las deficiencias en cuanto a su calidad y que sin duda saltaban a la vista. Aun así, no se conocen quejas en este sentido emitidas por los capitanes generales.

La falta de voluntad para cumplir la tarea es evidente en algunos casos. Se sabe por ejemplo que las edades de las personas eran registradas de forma bastante precaria. No había preocupación por conocer con precisión los años que los encuestados tenían. Por lo tanto, era normal que la evolución de las edades declaradas por cada individuo variara de año en año de manera poco creíble, siendo tan sólo un estimativo de edad. Pero, sorprendentemente, el serial de los padrones de población de la villa de São Luiz de Paraitinga, en el valle del Paraíba paulista, cuenta con ejemplares para la década de 1810 en el que la edad de las personas aumenta con los años con gran regularidad. Queda de principio la impresión desprevenida de un estudio minucioso y exacto. ${ }^{13}$

\footnotetext{
12 De allí podemos entender las razones de las quejas de los capitanes generales contra los repetidos retrasos en la finalización de esos padrones.

13 De acuerdo al reglamento, las edades eran declaradas en otro tipo de documentos tales como: testamentos, inventarios y escrituras; con años alrededor de los treinta, poco o más o menos; con una gran tendencia a ser redondeas, es decir, terminarlas en cero o cinco.
} 
Por lo tanto, los citados padrones eran meramente perfectas falsificaciones, el resultado de un astuto recurso simplificador. De hecho, no se realizaron los estudios de campo pertinentes y los funcionarios locales responsables por el trabajo, tan sólo se preocuparon por reproducir la lista del año anterior, teniendo cuidado en añadir un año a las edades declaradas, sin mayores elevaciones. El resultado es visible: falsa regularidad en la evolución de las edades y manejo de cifras inconsistentes en cuanto a la producción agrícola, copiadas llanamente de los listados precedentes. Lo que podría parecer una mejora en la calidad de la encuesta era, de facto, un engaño. La detección del problema sólo fue posible por la manifestación de lo obvio: niños que nacían dejaban de ser incluidos por años consecutivos, de la misma forma como los que fallecían "insistían" en permanecer en los padrones. De repente, al cabo de unos años, cuando finalmente otro padrón volvió a ser eficazmente erigido -muy probablemente después de la advertencia por las problemáticas anotadas-, surgieron niños con dos, tres y cuatro años de edad, al mismo tiempo en que desaparecieron los contingentes de fallecidos de los años anteriores. Teniendo en cuenta esta práctica, hay que pensar que el último padrón de esta serie incongruente acumuló un accionar significativo de errores. Si es utilizada para la construcción de pirámides de edad, proporcionaría resultados fuertemente deformados para la representación de la población infantil y la sobrerrepresentación de los ancianos. O si fuera construido a partir de estas listas el análisis acerca de la reproducción en los hogares, tendría una estabilidad poco realista.

La declaración de la condición racial también constituye una problemática en el análisis de los padrones. Las variaciones entre los términos de prieto y negro, o entre pardo y mulato, son bastante recurrentes y merecen un estudio más exhaustivo. Las diferencias en la adopción de estas formas se dieron a lo largo del tiempo, con las categorías de negro y mulato reemplazando progresivamente a las de prieto y pardo después de la Independencia. Pero nada se sabe acerca de las posibles diferenciaciones regionales, cuestión que aún no se ha investigado.

Con respecto a la actividad económica de los hogares, se debe ser muy cuidadoso a la hora de realizar cualquier análisis. A menudo la información que presenta se relaciona con la actividad ejecutada por el jefe de la familia, con raros indicios de otras ocupaciones desarrolladas por los hijos adultos, personas agregadas e 
incluso esclavos. Como la gran mayoría de los hogares se dedicaban principalmente a la agricultura, lo habitual era indicar también la producción de géneros obtenidos por año censado, así como de las eventuales transacciones efectuadas en el mercado local. Todos estos informes que abarcaron pueblos enteros, detalladamente y durante años, son sin lugar a dudas de un valor incalculable. Es posible con tales series acompañar la evolución económica de los hogares e incluso saber acerca de la posesión de esclavos a lo largo de los años, relacionándolos con el ciclo de la vida familiar y con la disponibilidad de fuerza de trabajo libre o cautiva. Es en este aspecto que los padrones de población son un corpus documental prácticamente únicos, permitiendo algunas líneas de análisis más profundas, que de las que son obtenidas a través de los inventarios post mortem. ${ }^{14}$

Sin embargo, la preocupación por la calidad de los datos debe ser tomada en cuenta. La primera cuestión por considerar debe ser con respecto a los criterios adoptados en el momento de estudiar la información. A excepción de los años de 1765 y 1767, así como de algunas fechas específicas en la década de 1770, la información de carácter económico se manifiesta de manera sistemática sólo a partir del decenio de 1790. Desde entonces, se empieza a juzgar como necesaria para hacer identificaciones (en su momento, por razones estratégicas de gobierno), la disponibilidad de productos agrícolas en todos los pueblos, junto con el reconocimiento del contingente humano. Era de sumo interés conocer la oferta de alimentos, por lo que significaba para el sostenimiento de las tropas y para poder poner en práctica políticas de desarrollo de la agricultura. De este modo, la mirada de la Corona iba dirigida casi que exclusivamente a las actividades agrícolas, relegando a un papel secundario, o incluso haciendo caso omiso, al informe de actividades relacionadas con el tropeirismo, las artesanías, y en cierto modo, con el comercio.

La mayor o menor calidad de la información económica contenida, también parece estar relacionada con la preocupación y la dedicación de las personas que

14 Estos tendrían, hipotéticamente, la gran ventaja de proporcionar el costo por cada esclavo, a pesar de las inconsistencias, muy evidentes, de esos valores. Por otra parte, los inventarios raramente indican la edad del señor, lo que dificulta enormemente el análisis a la tenencia de esclavos en el contexto del ciclo de vida de sus dueños. Aunque se sabe de antemano que, probablemente, los registros de esclavos inventariados sean muchas veces tomados de una fase de recesión económica del esclavista, redactadas como consecuencia de las dificultades que se asomaban con la vejez, sumadas a la ineludible obligación de repartir la de dote para cada hijo. 
realizaban la encuesta. De ahí parte el hecho de que se pueda encontrar, en un mismo padrón, dos compañías de ordenanzas cuyas listas fueron elaboradas con niveles de detalle absolutamente divergentes. Por lo tanto, se puede inferir que los criterios en la construcción de los censos podían variar con el tiempo debido a las nuevas directrices recibidas, pero también, al cambio de funcionarios locales quienes se encargaban de las encuestas.

Como resultado, nos enfrentamos a la dificultad de entender el significado de ciertas ocupaciones. Quienes describen las labores no eran empadronados por las autoridades centrales del gobierno colonial, dando lugar a muchas interpretaciones de la más diversa índole. ¿Cómo definir las diferencias o similitudes entre labradores, agricultores, sembradores, plantadores de abastecimiento y plantadores de subsistencia? ¿Se relacionan a distintos niveles de producción, a condiciones de disponibilidad de mano de obra, a la posesión de la tierra, al acceso al mercado o al estatus social? La respuesta no es fácil, ya que se desconocen los conceptos empleados, si es que hubo algunos. Por ejemplo: ¿Qué decir de un labrador, que al año siguiente de una primera encuesta, es descrito como un individuo que planta para el abastecimiento? ¿Su condición ha cambiado o fue la observación del encuestador la que se alteró?.15

La impresión que nos deja es la de que muchas de esas denominaciones están relacionadas con la introducción de nuevas expresiones en el lenguaje de la época. El caso más notable es el de los señores de ingenios, que en algunos padrones de finales de la década de 1820 pasaron a ser denominados ingenieros (engenheiros). Cabe aquí resaltar la necesidad de suscitar una revisión al espacio geográfico en donde se llevaron a cabo los censos, del proceso de adopción de ciertas nue-

\footnotetext{
${ }^{15}$ La expresión plantador de abastecimiento (planta para o gasto) puede conducir a interpretaciones erróneas. Decir que dado el tipo de domicilio, vivía de la subsistencia, que no participaba del mercado local, es una colocación en lo mínimo problemática. En la práctica, era imposible que un labrador, por más humilde que fuese, no mantuviera relaciones con el mercado. Pequeños excedentes eran casi obligatorios, pues permitían el consumo de bienes faltantes en la producción doméstica, como la sal o las herramientas de trabajo tales como: los azadones, los cuchillos, las hoces, etcétera.
}

Dossier: Cuestionando las fuentes de archivos: padrones de población, familias y sociedades coloniales en Iberoamérica, ss. XVIII-XIX 
vas terminologías, -tal vez introducidas desde el exterior-, hasta llegar al uso corriente de los administradores coloniales. ${ }^{16}$

Las mismas dudas se ciernen sobre las descripciones de otras ocupaciones, tales como las artesanales (herreros, talabarteros, latoneros, costureras, hilanderas, carpinteros, entre otros), quienes también podían fungir alternativamente como agricultores. ¿A caso nos muestran un cambio de ocupación o, - lo que en este caso, sería lo más probable-, la preocupación de señalar otra faceta de la actividad económica familiar? La agricultura o la producción de alimentos, ligadas con ocupaciones artesanales, parecen haber sido bastante comunes, aunque las encuestas casi nunca den razón de esa realidad. Los troperos, por ejemplo, son raros en los padrones de Sorocaba, villa de importante actividad comercial de animales. Pero podemos notar su presencia (mal señalada) cuando en muchos hogares de agricultores se informa de que los jefes de familia se hallaban ausentes por estar en el sur; claramente ejerciendo las ocupaciones relacionadas a la trata y transporte de animales, mientras que el resto de la familia permanecía cultivando las tierras. En suma, se refleja en esta fuente, la priorización en la descripción de los cultivos y la falta de interés al declarar detalladamente otro tipo de oficio realizado, fuera este de carácter permanente o temporal.

La lista de ausencias en los padrones es amplia. Los traficantes de esclavos por ejemplo, son absolutamente inexistentes en estas fuentes. Por alguna razón, los comerciantes y los distribuidores no reportaban tales géneros en los censos de negocios, a pesar de que la actividad es central para cualquier economía esclavista. A lo sumo, mencionaban la compra o venta de algunos cautivos, pero evitando declarar el número de la mercancía en cautiverio, siendo esto último un ejercicio aparentemente sistemático e ineludible dentro del negocio. Quizás, este ramo de las actividades tampoco le interesaba a quienes elaboraban las encuestas, por razones que aún no resultan claras.

En otro extremo de la jerarquía social, las prostitutas eran las grandes ausentes, con la excepción, bastante llamativa, de la mención de una gran casa de me-

\footnotetext{
${ }^{16}$ No sería demasiado señalar también la necesidad de revisar el uso de las descripciones de expuestos (expostos) o expósitos (enjeitados) al referirse a los menores abandonados, o los topónimos de origen africano de los esclavos, que igualmente cambian con el tiempo y para un mismo individuo.
} 
retrices en el listado de Sorocaba en 1771. En este caso, aunque son descritas como tales para ese año, son identificadas como costureras, hilanderas y labradoras en los años inmediatamente anteriores y posteriores ${ }^{17}$. ¿Enmascaramiento de la actividad socialmente indeseable o fueron eventualmente las mujeres quienes vendieron sus cuerpos en caso de necesidad? ¿Serían prostitutas a tiempo completo o sólo por algunos momentos aquellas mujeres que, por debajo de la línea de pobreza, lo practicaban para subsistir? Sólo el contraste con otras fuentes, como los actos y delitos civiles, donde la prostitución aparece de manera más recurrente y explícita, permitiría rastrear con mayor precisión a aquellas mujeres invisibilizadas en los padrones de población.

De cualquier modo, se hace necesario trabajar con mucha precaución la información sobre las ocupaciones. Algunas veces, la escueta descripción no parece coincidir con la situación del hogar, como en el caso de la viuda Ana Maria de Toledo. La señora acompañada de dos hijas y dos hijos adultos, declara en 1816, haber vendido 50 cerdos. Por mayor que haya sido la cantidad de animales criados, nada justifica la posesión de 33 esclavos que se le contabilizaron. ${ }^{18}$ Existe un evidente desequilibrio entre la información de la actividad económica y la mano de obra disponible. Ciertamente, se tiene que admitir que esos esclavos debieron trabajar en el campo, ya que la viuda se declaró en reiteradas ocasiones como agricultora, pero sólo en una ocasión, en 1825, se le registraron a la venta 30 fanegas de fríjol. Es inevitable imaginar que un numeroso grupo de esclavos como este, incluso si se descuentan siete esclavos pequeños que tenía la señora, no podían estar dedicados únicamente a la producción para el consumo del hogar. No hay ninguna lógica económica para justificar la inversión en tal cantidad de esclavos sin ningún beneficio de producción para el mercado. El problema radica por supuesto, en la insuficiencia de la información en los padrones de población; sucinta en exceso, sugiriendo que la actividad económica era menor que la real.

17 Carlos Bacellar, Viver e sobreviver em uma vila colonial: Sorocaba, séculos XVIII e XIX, São Paulo, Annablume/Fapesp, 2001, p.170.

18 APESP, Lista nominativas de habitantes de São Luiz do Paraitinga para $1816,2^{\mathrm{a}}$ Companhia de Ordenanças, f.285.

Dossier: Cuestionando las fuentes de archivos: padrones de población, familias y sociedades coloniales en Iberoamérica, ss. XVIII-XIX 
El seguimiento a la trayectoria de una familia y su hogar permite entrever los problemas en cuanto a la calidad del trabajo recogido en el padrón. Si se observa el domicilio del agricultor Antonio Ferreira da Cruz se percibe que su condición de pequeño productor parece haber mejorado en casi 30 años que se le censa, entre 1799 y 1828. El registro para el año de 1801 es comúnmente más elaborado, el más completo en términos de información. Allí se da a conocer que Antonio vende en el mercado 30 arrobas de tocino, 50 alqueires de maíz, cinco fanegas de fríjol y que compró cinco fanegas de sal, indispensables para conservar el tocino. A partir de ese año en adelante, las informaciones acerca de la actividad económica de la unidad familiar son cada vez más deficientes. La producción de tocino fue declarada hasta 1807, siempre en el mismo nivel aproximado. El maíz sólo aparece dos veces, en 1803 (140 fanegas) y 1807 (ídem); el fríjol en los mismos años, 1803 (cinco fanegas) y 1807 (seis fanegas). La única referencia que se mantiene es la compra de sal, dado que era un asunto que le importaba a las autoridades, preocupadas por la gestión del monopolio de venta mantenida por la Corona. Es a través de la adquisición de la sal que se puede suponer que la actividad económica de esta familia se incrementó en los años siguientes: de tres alqueires comprados en 1806, hubo un aumento progresivo hasta los 16 alqueires comprados en 1816, señal bastante fuerte que confirma que la actividad de la salazón de carne de cerdo para la producción de tocino había crecido sólidamente. ${ }^{19}$ Por lo tanto, a pesar de las informaciones incompletas, la posibilidad de analizar la actividad económica se puede lograr.

\section{Organización interna de los hogares}

Los padrones de población tienen por base descriptiva a los hogares o lares (fogos). Allí, hipotéticamente, se tendría descrita una unidad de trabajo, ya fuese ella una propiedad rural, la casa de un campesino que vive de favor en tierras ajenas, o un morador del núcleo urbano. La aparente evidencia y simplicidad de este formato puede sin embargo ocultar ciertos aspectos más complejos de la organización de una comunidad determinada. Pero, ¿Hasta dónde se puede avanzar?

${ }^{19}$ APESP, Listas nominativas de São Luiz do Paraitinga para 1799 a 1828.

Dossier: Cuestionando las fuentes de archivos: padrones de población, familias y sociedades coloniales en Iberoamérica, ss. XVIII-XIX 
Una primera consideración iría en el sentido de lo que significa un lar ( $f_{0}$ go). Se puede considerar que se circunscribía en una unidad económica de trabajo: todos los allí presentes trabajaban juntos, en torno a actividades organizadas y encaminadas a mantener al núcleo familiar. Pero de ninguna manera este lar puede tipificarse de forma automática como si tuviese una efectiva posesión sobre la tierra. El jefe del hogar podía perfectamente estar registrado como agricultor, pero no como propietario de la tierra que explotaba. $\mathrm{Y}$ este aspecto de fundamental importancia, no era el objeto de observación en los padrones de población. Como resultado, no se sabe quiénes eran los dueños y quiénes vivían del favor de los mismos.

El cruce entre los padrones de población y los Inventarios de Bienes Rústicos de 1817,- verdadero censo de las propiedades promovido en cada villa de la capitanía-, apunta de manera contundente hacia la disparidad entre el número de lares y el de propiedades. ${ }^{20}$ La conclusión es bastante obvia: habían muchos más hogares sin tierra de los que cabría esperar en una sociedad fundamentalmente rural. A pesar de que una vieja tradición historiográfica defiende la abundancia de tierras en el período colonial, esta intersección de fuentes, de hecho, señala mucho más allá de lo abundante y confirma la concentración de las mismas, lo que deja claro que existían muchas tierras y pocos propietarios. ${ }^{21}$

Ahora bien, esto significa que la gran mayoría de los agricultores, labradores, sembradores, entre otros trabajadores rurales, no tenían tierras propias; tan sólo tierras cultivadas con autorización, es decir, a favor de terceros a quienes pagaban por el uso del suelo. ${ }^{22}$ Eran técnicamente agregados, pero de una categoría escasamente descrita en los padrones de población, esto es: como agregados que vivían en tierras ajenas y bajo distinto techo. Hay una clara diferencia por lo tanto,

\footnotetext{
${ }^{20}$ Esta serie bastante interesante también, se encuentra bajo la preservación del Archivo Público del Estado de São Paulo.

${ }^{21}$ La frontera abierta orientada hacia el interior no permitía -aun así- que los excedentes demográficos se establecieran allí libremente. Avanzar más allá de esos límites imaginarios significaba desconectarse peligrosamente del contacto con los centros de población y correr el riesgo de ataques indígenas. Por supuesto, muchos prefirieron la opción más segura de la agregación.
}

22 Este pago podía ser en moneda, en especie o incluso con trabajo.

Dossier: Cuestionando las fuentes de archivos: padrones de población, familias y sociedades coloniales en Iberoamérica, ss. XVIII-XIX 
para con otra categoría de agregados mucho más notable, que vivían subordinados dentro de un domicilio y bajo un mismo techo. Eran individuos o familias que ofrecían su trabajo y compartían la vida doméstica diaria. Se presentan con una condición distinta de aquellos que labraban la tierra por cuenta propia, en otras áreas, con producción autónoma, y que de vez en cuanto podían colaborar con esfuerzos conjuntos (mutirões), como forma de retribuir al permiso de cultivo. Este fue el caso de Antonio Dias de Camargo, de 21 años, blanco, casado con Maria, de 30 años, y con un hijo, Benedito, de apenas un año. Jóvenes y recién casados, viviendo en dependencia de la tierra de terceros, de acuerdo a la declaración de ser un plantador de abastecimiento (planta para o gasto) de favor. ${ }^{23}$ Este mismo hogar vuelve a aparecer en el padrón de 1828, pero con el jefe de familia sólo descrito como agricultor, sin que se sepa si hubo algún cambio en la condición de acceso a la tierra. ${ }^{24}$ En algunos casos, la agregación a tierras ajenas se explica mejor: en 1828, Antonio José da Costa se declara agricultor que vive a favor del Sargento Mayor Salvador Gomes. ${ }^{25}$

Agregados bajo el mismo techo podían ser comúnmente los parientes ancianos o los desvalidos, acogidos por caridad familiar y que contribuían en la medida de lo posible con el esfuerzo común de sostenimiento. Pero los que recibieron tierras para cultivar por cuenta propia debían tener, obligatoriamente, la disponibilidad de mano de obra suficiente para la supervivencia independiente e incluso podían contar con sus propios esclavos. En esta categoría se podrían incluir también a los hijos que iniciaban una vida autónoma, solteros o casados, pero que aún dependían de las tierras paternas para subsistir.

Para la villa de Sorocaba se dispone de un padrón de población bastante excepcional para el año de 1772, donde no había (por órdenes venidas de Lisboa) preocupación por indicar con precisión las dos categorías de agregados; tan sólo,

\footnotetext{
${ }^{23}$ APESP, Lista Nominativa de São Luiz do Paraitinga para 1825, $4^{\text {a }}$ Companhia de Ordenanças, f.567.

24 APESP, Lista Nominativa de São Luiz do Paraitinga para $1828,4^{\text {a }}$ Companhia de Ordenanças, f.588.

${ }^{25}$ APESP, Lista Nominativa de São Luiz do Paraitinga para $1828,3^{\text {a }}$ Companhia de Ordenanças, f.343.
}

Dossier: Cuestionando las fuentes de archivos: padrones de población, familias y sociedades coloniales en Iberoamérica, ss. XVIII-XIX 
saltándose la regla, indicando a aquellos como agregados domésticos. ${ }^{26}$ Fue así el caso de un labrador, Francisco de Souza, dueño de nueve esclavos y cultivador de maíz, fríjol, maní y algodón, quien declara plantar en tierras ajenas. Estas informaciones permiten un análisis más profundo del fenómeno, con la adición de los moradores de estos hogares sin tierra en la contabilidad del total de agregados existentes en la villa. Por lo tanto, la magnitud de la diferencia del fenómeno social se hace notable de esta manera: mientras que los agregados domésticos sorocabanos representaron el 18,8\% de la población libre, los agregados autónomos, o en la roza como se les denominaba, concentraron otro contingente del $14,6 \%$ de la población libre. Tomados en conjunto, constituyeron el 33,4\%, respaldando aún más la tesis de la concentración de la tierra, donde cerca de un tercio de los libres carecían de dominios propios. ${ }^{27}$

Más allá del acceso a la tierra, es preciso darse cuenta en los resquicios de los padrones, de los indicios de otras realidades detrás de la presencia de agregados bajo un mismo techo. En ciertas coyunturas, se revelaron situaciones bastante sospechosas de incrementos de los moradores dentro de los hogares. Como en el caso de las personas instaladas a lo largo del conocido Camino de Goiás, ruta que partía de la capitanía de São Paulo y que -apuntando hacia el noroeste- llegaba hasta Vila Boa, en la capitanía de Goiás. Los padrones de población allí levantados, reportaron un fenómeno muy recurrente de domicilios que se vaciaban y llenaban constantemente, en un movimiento que podríamos definir como pendular, de recurrentes idas y vueltas. Se puede distinguir por tanto que estos hogares se concentraban a la orilla de dicho camino, alrededor de posadas, separadas entré sí por algunas buenas leguas de distancia. Si bien, lo que ocurría era que para cada posada había un colono pionero y su domicilio matriz y en relación a su figura, se producía una variación en el formato de elaboración del padrón: en un año determinado, el censado agrupaba a todos los demás moradores en su gran casa como agregados bajo

\footnotetext{
${ }^{26}$ La suposición de una orden superior se debe a la existencia de padrones de calidad similar para otras villas, en esas mismas fechas.

27 Carlos Bacellar, “Agregados em casa, agregados na roça: uma discussão”, en María B. Silva, (coord.), Sexualidade, família e religião na colonização do Brasil, Lisboa, Livros Horizonte, 2001, pp.187-199.
} 
su cargo, sin duda por ser el propietario principal y autorizar la residencia en sus predios. Para el año siguiente, de una manera diferente, cada unidad doméstica se registró como un hogar autónomo, separado, sin ni siquiera mencionar el vínculo con el fundador del asentamiento.

El caso de Januário da Silva Bueno, presentado en el cuadro 1, no se puede explicar por cualquier movimiento de cambios en la composición de su hogar, sino, por maneras distintas de clasificar a los moradores de su posada. ${ }^{28}$ Se puede decir así, que los criterios para realizar los padrones eran inestables.

Tabla 1: Agregados en el hogar de Januário da Silva Bueno, Camino de Goiás 29

\begin{tabular}{|c|c|}
\hline Años & Agregados \\
\hline $\mathbf{1 7 8 2}$ & 31 \\
\hline $\mathbf{1 7 8 3}$ & 2 \\
\hline $\mathbf{1 7 8 4}$ & 8 \\
\hline $\mathbf{1 7 8 5}$ & 6 \\
\hline $\mathbf{1 7 8 6}$ & 20 \\
\hline $\mathbf{1 7 8 7}$ & 7 \\
\hline $\mathbf{1 7 8 9}$ & 32 \\
\hline
\end{tabular}

Fuente: APESP, Grupos de Población de Moji Mirim, nº de orden 116 e 116-A.

A pesar de esta práctica que alteraba el perfil de los hogares en algunos padrones, no se puede negar la ocurrencia de los movimientos de población. Era bastante común la movilidad de algunos individuos o familias, que aparecían y desaparecían de un hogar determinado, dificultándose así su rastreo. No fue por tanto, una inexactitud de la información o una opción del censor. ${ }^{30} \mathrm{Si}$ la restricción al acceso a la tierra era una realidad, los desposeídos tenían que decidir entre agregarse

28 C. Bacellar, "Agregados em casa”, p.194.

${ }^{29}$ C. Bacellar, "Agregados em casa", p.194.

30 Cabe resaltar también, la relativa rara mención de individuos caracterizados como huéspedes (hóspedes), ciertamente personas en tránsito desde sus sitios bastante alejados de las villas, o familiares que por alguna razón venían a pasar alguna temporada en el domicilio. 
a una tierra ajena o migrar hacia zonas de fronteras, donde teóricamente el acceso a la tierra vacante podría ser más fácil.

En ese sentido, la agregación también servía como un importante mecanismo de refuerzo social, en donde aquellos ya previamente establecidos acogían a parientes, conocidos o a simples entrantes, -como se les llamaba en el lenguaje de la época-, en busca de un espacio para instalarse. Jóvenes recién casados también surgían en esa situación: permanecían como agregados junto a sus padres o suegros, mientras construían su nuevo espacio -en las propias tierras de la familia o en la de terceros- como agregados o en terrenos baldíos. La tierra a ser explotada debía ser segada y cultivaba, y sólo entonces, ya productiva, podría acoger a nuevos residentes. Antes de eso, la agregación les brindaba refugio, a cambio ciertamente, de la contribución a la fuerza laboral.

Se tuvo ocasión de examinar un caso interesante en ese sentido, el de la viuda Ana Teixeira. Vecina de Piuhi, capitanía de Minas Gerais, con sus siete hijos planeó la migración familiar hacia la villa de Franca, en São Paulo, gracias al respaldo de un cura, quien los ampararía en aquel pueblo. Cada año, desde 1804, algunos de los hijos de Ana fueron a Franca y se establecían en los terrenos del párroco, en los que fueron autorizados para abrir rozas para su propio sustento. Este soporte material y operativo para asegurarse la alimentación, les permitió que también se ubicaran y desbravaran terrenos baldíos cercanos. Hechos los trabajos de limpieza de cada temporada, se devolvían a la casa materna, dándole cuentas a la madre y preparando el retorno para el año siguiente. Sólo cuando la tierra deseada ya estuvo bien cortada y labrada, y dio los primeros frutos, fue cuando la madre y todos sus hijos se desplazaron definitivamente para Franca. Sería interesante preguntarse cómo la presencia estacional de los hijos de Ana Teixeira en Franca fue registrada en los padrones: como agregados del sacerdote, o como entrantes en el propio domicilio. O simplemente, no estaban presentes y eran por tanto ausentes justo en el momento de hacer el padrón. En cualquier caso, hay abun- 
dante evidencia de que esta práctica era bastante común, parte de un mecanismo más amplio de reproducción social de aquella sociedad agraria. ${ }^{31}$

Esa circulación de individuos y familias, tanto en el espacio restringido de una villa como en el más amplio de la capitanía, es una característica de nuestras poblaciones coloniales, aún poco develadas. Aunque los jefes de familia tienen su naturalidad comúnmente definida, queda mucho por aprender acerca de los movimientos migratorios de la época y su relación con la disponibilidad de tierras, la actividad económica y la barrera representada por las regiones agrestes más distantes, no necesariamente sujetas a la ocupación.

\section{La familia}

Los padrones de habitantes han posibilitado interesantes análisis acerca de la familia en el período colonial. Hoy en día se puede afirmar con seguridad que la mayoría de los hogares de las villas paulistas se componían de una familia nuclear, eventualmente con agregados y esclavos; y una minoría, que se podría definir como de familia extensa. ${ }^{32}$ No obstante, algunas conclusiones sobre el concubinato o la ilegitimidad de madres solteras permanecen todavía poco exploradas en los padrones. Hay que reconocer que estas fuentes son relativamente poco explicitas en ese sentido, especialmente en relación con el concubinato y la ilegitimidad marital, pues sus redactores tenían escaso interés por describir semejantes prácticas cotidianas.

En realidad, los padrones se reducen a retratar a las comunidades compuestas por hogares encabezados por parejas, personas solteras o viudas. No hay duda sin embargo, que muchas parejas en concubinato o en uniones maritales informales, vivían en situaciones relativamente estables, sobre todo si no traspasaban los

31 Carlos Bacellar, "Desbravadores do sertão: Família e posse da terra em zonas de fronteira em São Paulo, Brasil, séculos XVIII e XIX”, Ponencia presentada en el $51^{\circ}$ Congreso Internacional de Americanistas, Santiago de Chile, 2003, 18p.

32 M. L. Marcílio, Crescimento demográfico, pp.100-104.

Dossier: Cuestionando las fuentes de archivos: padrones de población, familias y sociedades coloniales en Iberoamérica, ss. XVIII-XIX 
límites de lo público o escandaloso. No eran pocas las parejas en esa condición, pero los registros son deliberadamente vagos al respecto. ${ }^{33}$

En ese sentido, debemos tener en cuenta la relación entre concubinato y madres solteras, que era mucha, constatado así, tanto en los padrones como en los registros de bautismo. ¿Quiénes eran y en dónde se registraron los padres de los hijos productos de esas relaciones? Algunas actas de bautismo dejan entrever que el vicario conocía al padre, al dejar escapar declaraciones en los siguientes términos: hijo de Fulano, quiero decir, de padre desconocido. Quizás eran hombres que serían ocultados y protegidos en el bautizo, ya que no eran escandalosos y vivían en paz dentro de la comunidad. Cabe en este caso tratar de examinar cómo esta misma pareja informal fue tratada en los padrones de población, muy a pesar de su condición ¿Con la mención esquiva de la unión o el simple nombre de la madre soltera? Esta posibilidad de investigación allanaría el camino para la comprensión de los mecanismos de aceptación del concubinato, fuese por la reiteración del ocultamiento paterno o por su reconocimiento. La pregunta es entonces inevitable: ¿Cómo habrían sido presentadas tales uniones en los padrones de población? como si fueran parejas aparentemente regulares, tal como aquellas formalizadas en matrimonio, o a través de la figura de las madres solteras, con sus compañeros ocultos o insertados en otros hogares, con su prole representada como hijos o agregados. En pocas palabras ¿Hasta qué punto habría una proximidad de criterios entre los padrones (un documento elaborado por los oficiales de ordenanzas) y las actas de bautismo, surgidas de las propias manos de los párrocos?

33 Sobre las uniones consensuales en el Brasil colonial, ver F. Torres Londoño, A outra família: concubinato, igreja e escândalo na colônia, São Paulo, Edições Loyola, 1999.

Dossier: Cuestionando las fuentes de archivos: padrones de población, familias y sociedades coloniales en Iberoamérica, ss. XVIII-XIX 


\section{La cuestión del territorio}

Los padrones de población son también una fuente de gran importancia para el estudio de la organización administrativa y territorial de las villas dentro de la capitanía. Reflejan antes que nada la estructura de las compañías de ordenanzas, ya que se producen por orden del capitán general con responsabilidades compartidas con los capitanes mayores, quienes comandaban esas fuerzas militares. Dentro de cada compañía de ordenanzas, se refleja la subdivisión de las mismas por escuadras, cada uno bajo la supervisión de su respectivo lugarteniente.

Esa estructura organizativa de las compañías -y por tanto también de los padrones-, coincide de manera general con la ubicación de los distritos rurales. Cada uno respondía por un área geográfica determinada, controlada a su vez por las mismas escuadras. La identificación correcta de esta vigilancia permite trabajar dentro de ciertos límites, con la posibilidad de identificar las relaciones de vecindad, inspeccionando quién vivía relativamente más cerca de quien. En este proceso, el acceso a la tierra se erige como un elemento fundamental a ser considerado.

En ciertas situaciones, los hijos recién nacidos podían lograr obtener una parte considerable de tierras para cultivar dentro de la propiedad paterna. En consecuencia, el registro constataba de manera bastante obvia la inclusión de los hijos ya fuese como agregados o después de separados (en sus hogares propios), como vecinos; ambos casos, dentro del domicilio paterno. Todos bajo el control de una escuadra, en el mismo distrito.

De esta manera, el seguimiento de los padrones, año tras año, permitiría continuar a priori, el proceso de expansión demográfica y de la tierra, por el surgimiento de nuevos hogares dentro de un espacio territorial definido, circunscrito a una escuadra de las ordenanzas. Más complicado aún, es hacer realidad una lógica geográfica en las encuestas. La secuencia de los hogares no se mantiene necesariamente de un año a otro, volviéndose complicado detectar un orden en los estudios, que se traduzca en un trayecto claro por las rutas locales en el proceso de visitar cada propiedad. A veces da la impresión de que los residentes del lugar llegaban hasta donde el encuestador y no este hacia ellos; resultando inevitablemente, en la no repetición de una continuidad lógica de los domicilios en el padrón. Cualquiera

Dossier: Cuestionando las fuentes de archivos: padrones de población, familias y sociedades coloniales en Iberoamérica, ss. XVIII-XIX 
que fuese el procedimiento, lo cierto es que un hogar jamás recibía la misma numeración secuencial de un año a otro. ${ }^{34}$

Aun así, el pertenecer a una misma escuadra garantizaba la proximidad de los domicilios entre sí, permitiendo avanzar en el análisis de las relaciones de solidaridad y de la sociabilidad en general entre los habitantes. Una vez más se sugiere que los ricos datos de los padrones sean complementados a través del cruce de información obtenido con otras fuentes. Una posibilidad prometedora, aunque difícil, es el de contrastar los padrones con fuentes judiciales, donde relatos de actividades cotidianas que dieron lugar a crímenes o conflictos -trabajos comunales, fiestas, convivencia en las ventas de las orillas de las vías fronterizas-, permitan observar las formas posibles de cohabitación.

Esta forma de análisis también permite avanzar en el estudio del compadrazgo como un fenómeno complejo. La elección de los padrinos de los niños y los esclavos puede ser observada a través de la proximidad física de las viviendas de los encuestados. Dicha escogencia de padrinos o madrinas podría estar, por supuesto, influenciada por la vecindad, por la confianza en el compañero de coexistencias diarias y lógicamente, por los vínculos de parentesco. Una pareja de esclavos que se escogían respectivamente de casas vecinas, así identificados justamente en los padrones, permiten indagar acerca de las posibilidades de contacto y convivencia entre los cautivos de las propiedades cercanas, de su circulación en el espacio de la villa o de las relaciones inmediatas entre sus amos.

\section{Los mapas de población}

Los llamados mapas de población no son más que series de cuadros estadísticos que acompañan a los padrones. Podían ser de carácter demográfico al resumir la población contenida en las encuestas, de acuerdo a los grupos de edad previamente

\footnotetext{
34 Basta un simple ejemplo para aclarar este tema: João da Silva Coutinho, vecino de São Luiz de Paraitinga, tenía su hogar anualmente enumerado desde de 1793 , en la $2^{\mathrm{a}}$ Compañía de Ordenanzas, con la siguiente secuencia: 103, 90, 93, 76, 153, 282, 292, 91, 130 y así sucesivamente.
}

Dossier: Cuestionando las fuentes de archivos: padrones de población, familias y sociedades coloniales en Iberoamérica, ss. XVIII-XIX 
empadronados. Desde la década de 1790, se comenzaron a desarrollar también en ellos estadísticas económicas, en lo concerniente a la compra y venta de mercancías, sus precios, volúmenes, orígenes y destinos.

Regularmente usadas como fuentes informativas, tales mapas sirven de importante referencia. Su elaboración anual ha permitido la construcción de series de datos en bruto, presentando las tendencias demográficas y económicas de una villa en específico. Sin embargo, hay que tener en cuenta que este tipo de documento contiene sistemáticamente errores en la tabulación y en los criterios. En la presentación de la población total por grupos de edad, llaman la atención los errores de sumatoria. La repetición del proceso de conteo, a partir de los datos netos de las encuestas, habitualmente conduce a resultados diferentes, algunos, de cierta consideración.

Incluso los totales brutos de los domicilios pueden experimentar problemas. El montaje de los padrones podría conducir de principio a confusiones en el proceso de enumeración de los hogares. La ausencia de anotaciones, numeraciones repetidas o saltadas, sobre todo al pasar de una página a otra, son bastante comunes. Algunos de estos errores se acumulaban, dando lugar a diferencias significativas, lo que hace muy recomendable la comprobación detallada de las cifras evaluadas.

En la instalación de los cuadros de población, los grupos de edad establecidos son de por sí problemáticos. Los conjuntos definidos de o a 5 años, de 5 a 10, de 10 a 20 y así sucesivamente, permite que se cuestione dónde un niño de cinco años estaría inserto. Aunque se sabe de antemano que las edades señaladas en los padrones son aproximadas, no se puede olvidar que los grupos así estructurados aumentan -todavía más-, la incertidumbre de los resultados de un análisis de carácter demográfico. Si se conservan los padrones, no estaría demás sugerir el reconteo, a pesar de las dificultades que entraña. El estudio demográfico de las poblaciones del pasado no puede prescindir, por supuesto, de la exactitud posible de los datos.

También, con respecto a la calidad de la información, se debe prestar atención a los problemas más comunes con los nombres propios. Cuando se tiene la intención de hacer un seguimiento prolongado de individuos o familias, siempre es más fácil seguir los trazos de aquellos de mayor relevancia en la sociedad, como a los grandes terratenientes y a los religiosos. Instalados en grandes casas con mu- 
chos esclavos, son fácilmente visibles en los padrones. En situación diferente se encuentran los sectores más humildes de la población. Por no citar a los obvios, que serían los esclavos, se tendría a la gran masa campesina, entre los cuales se incluyen sus homónimos restantes. Las mujeres viudas o solteras de baja extracción social, eran habitualmente identificadas por su primer apellido, acompañada de sus nombres devocionales muy repetitivos. Ana de Jesus y Maria da Conceição, son dos ejemplos donde se confunden algunas mujeres. Pero igual los hombres estaban en similares circunstancias. Todo resulta en una cierta dificultad de seguimiento nominal, agravada por la imprecisión en la consignación de los datos. Los apellidos eran inventados sin ceremonia. Tal como Inácio Garcia da Fonseca, vecino de São Luiz de Paraitinga, que en otras ocasiones declaraba como Inácio da Fonseca Garcia. Pero el mismo individuo aparecía también como Inácio da Fonseca e Inácio Garcia, volviéndose cada vez más esquivo el rastreo. Por otro lado, la clasificación de esas informaciones, especialmente de las diversas grafías posibles para un nombre, es susceptible de análisis de la mano de la lingüística, centrada en el cambio de las gramáticas y las ortografías de la lengua portuguesa. Este procedimiento, sin embargo, dificulta el orden alfabético de los nombres y es una cuestión a ser tomada en cuenta cuando se intente construir un banco de datos nominales.

En conclusión, se reafirma el enorme potencial de los padrones de población, especialmente con respecto a las grandes series conservadas para la capitanía de São Paulo. Faltan hasta la fecha, mayores exploraciones del potencial de estudios prolongados, que se facilitan gracias a la continuidad temporal de estos documentos, pero que por lo general son más trabajados a través de cortes transversales por ciertos años. Sólo la posibilidad de acompañar las historias de vida a lo largo de setenta años permite vislumbrar la excepcionalidad de la fuente. Única en su cobertura geográfica y temporal en el mundo americano, resulta esencial para el análisis de los procesos migratorios y de la organización de la distribución de la tierra, posibilitando observar las estrategias familiares, el mestizaje y la esclavitud en el contexto de la economía azucarera y más adelante, de la cafetera. Este es el reto. Aún queda mucho por desentrañar en estas páginas bien conservadas de nuestro pasado colonial. 


\section{Bibliografia}

\section{Fuentes primarias:}

Arquivo Público do Estado de São Paulo (APESP).

\section{Fuentes secundarias:}

Bacellar, Carlos de Almeida Prado, "Agregados em casa, agregados na roça: uma discussão", in Silva, Maria Beatriz Nizza da (coord.), Sexualidade, família e religião na colonização do Brasil, Lisboa, Livros Horizonte, 2001, pp.187199.

Bacellar, Carlos de Almeida Prado, "Desbravadores do sertão: Família e posse da terra em zonas de fronteira em São Paulo, Brasil, séculos XVIII e XIX”, Artículo presentado en el $51^{\circ}$ Congreso Internacional de Americanistas, Santiago de Chile, 2003, 18 p.

Bacellar, Carlos de Almeida Prado. Viver e sobreviver em um vila colonial: Sorocaba, séculos XVIII e XIX, São Paulo, Annablume/Fapesp, 2001.

Bellotto, Heloisa L., Autoridade e conflito no Brasil colonial: o governo do Morgado de Mateus em São Paulo, São Paulo, Alameda, $2^{\mathrm{a}}$ ed. revista, 1979.

Borrego, Maria Aparecida de Menezes, A teia mercantil: negócios e poderes em São Paulo colonial (1711-1765), São Paulo, Alameda, 2011.

Canabrava, Alice, "Uma economia de decadência: os níveis de riqueza na Capitania de São Paulo, 1765-67", in Revista Brasileira de Economia, Rio de Janeiro, 26(4): 1972. pp.95-123,

Marcílio, Maria Luiza, Crescimento demográfico e evolução agrária paulista, 1700-1836, São Paulo, Hucitec, Edusp, 2000.

Matos, Paulo Lopes, "O numeramento de Goa de 1720", in Anais de História de Além-Mar, vol. III, 2007, pp.241-324. 
Medicci, Ana Paula, Administrando conflitos: o exercício do poder e os interesses mercantís na capitania/província de São Paulo (1765-1822), Tese de doutoramento em História Social pela Universidade de São Paulo, 2010.

Torres Londoño, Fernando, A outra família: concubinato, igreja e escândalo na colônia, São Paulo, Edições Loyola, 1999.

Dossier: Cuestionando las fuentes de archivos: padrones de población, familias y sociedades coloniales en Iberoamérica, ss. XVIII-XIX 